\title{
Transformasi Budaya Ruwatan
}

\section{Bambang Soelistyanto}

Keywords: tradition, java, transformation, ethnoarchaeology, cultural anthropology

\section{How to Cite:}

Soelistyanto, B. Transformasi Budaya Ruwatan. Berkala Arkeologi, 16(1), 13-24. https://doi.org/10.30883/jba.v16i1.742

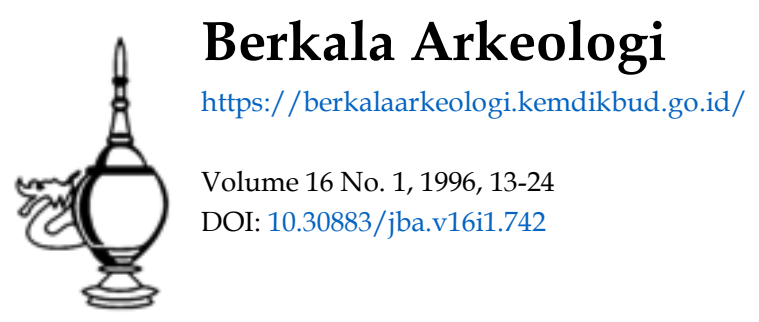

\section{cc) (i) (2)}

This work is licensed under a Creative Commons Attribution-NonCommercial-ShareAlike 4.0 International License. 


\title{
TRANSFORMASI BUDAYA RUWATAN
}

\author{
Bambang Sulistyanto \\ (Balai Arkeologi Yogyakarta)
}

\section{Pendahuluan}

Fenomena baru berupa upacara ruwatan, akhir-akhir ini sedang melanda masyarakat Jawa. Konsepsi ruwatan adalah upacara korektif yang dimaksudkan agar segala sesuatunya berjalan normal kembali Hal itu terjadi ketika rasio sudah sampai pada puncaknya dan tidak mampu làgi untuk memecahkannya. Dalam ruwatan selalu melibatkan manusia sukerto atau manusia "panas" yang menurut kepercayaan Jawa menjadi mangsa Bhatara Kala. Manusia atau bocah sukerto inilah yang menjadi obyek penderita yang hanya dengan upacara ruwatan mereka dapat dikembalikan menjadi subyek pelaku. Pergantian fungsi dari obyek penderita ke subyek pelaku tersebut menurut Damardjati (1992:6), karena kacaunya struktur pangkal dan pendukung nilai atau rusaknya pola konsekuensi yang berakar pada kesalahan manusia atas hakekat kala atau waktu. Oleh karena itu prosesi ritual dalam ruwatan yang terpenting adalah terselenggaranya selamatan dan pertunjukkan wayang kulit berlakon Murwakala. Dengan demikian ruwatan akan memeriukan biaya besar yang tidak semua orang dapat melakukannya.

Upacara ruwatan yang terjadi sekarang ini banyak dilakukan secara masal. Penyelenggaranya pun tidak terbatas pada lembaga yang bergerak dalam bidang kebudayaan, tetapi juga oleh lembagalembaga lainnya. Bahkan banyak disponsori oleh perusahaan-perusahaan tertentu di bawah naungan yang berslogan pelestarian nilai budaya tradisional atau oleh hotel-hotel berbintang lainnya. Sebagai contoh selama dua bulan (Mei-Juni 1996) di Yogyakarta telah berlangsung upacara ruwatan sebanyak empat kali. Uniknya, peserta bukan hanya -masyarakat Jawa saja tetapi dari luar Jawa pula (Kompas, 25 Juni 1996).

Sebagaimana terungkap dari judul di atas, tulisan ini bermaksud membahas perubahan nilai-nilai ruwatan dalam konteks kebudayaan yang dinamis. Gagasan pokok yang akan dikemukakan dalam tulisan ini adalah mengenai perubahan makna ruwatan yang mengalami pergeseran seiring dengan perkembangan masyarakat dalam mengidentifikasi kebudayaan. Hal tersebut didasarkan pada data 
filologis dan arkeologis yang memperlihatkan bahwa ruwat yang berarti membinasakan, menghancurkan, atau membebaskan telah ada dalam konsep keyakinan masyarakat Jawa sejak abad IX M. Bahkan lakonlakon ruwatan yang bermakna pelepasan, banyak menghiasi dindingdinding percandian di Jawa Timur.

Sehubungan dengan permasalahan di atas pertanyaan dasar yang muncul adalah, dari mana dan kemanakah arah budaya ruwatan yang berlangsung sekarang ini? Apakah budaya ruwatan sekarang ini ada kaitannya dengan ruwatan masa lalu, atau sebaliknya terlepas dan memiliki langkah tersendiri? Pertanyaan-pertanyaan dasar tersebut, tentu saja tidak mungkin dapat terjawab secara rinci dan memuaskan dalam tulisan singkat ini, namun beberapa segi penting akan dicoba dikemukakan melalui pendekatan historis-antropologis.

\section{Ruwatan Masa Lalu}

PJ. Zoetmulder dalam Old Javanese English Dictionary mengartikan ruwat sebagai membebaskan, menghapuskan atau menghancurkan (Zoetmulder, 1982:1578). Kata ruwat ditemukan pertama kali dalam kakawin Rãmayãna 20:5 yang ditulis pada masa kerajaan Mataram kuna sekitar abad IX M. Kata ruwat dalam kakawin ini memiliki arti hancur dalam konteks pertempuran yang berlangsung antara Rama dengan Rawana, khususnya dalam adegan Indrajit dengan Angada di Alengkapura. "Pupuh kuda sang Indrajid ruwat ikang rathâsāk rêmuk..." (menghantam kuda Sang Indrajid hancurlah kereta perangnya, menjadi pecah luluh lantak). Hal tersebut menunjukkan kata ruwat bersifat provan yaitu berupa benda -hancurnya kereta perang Sang Indrajit-

Demikian pula pada masa Kadiri sekitar abad XII $M$ kata ruwat banyak dipergunakan untuk menjelaskan sesuatu yang bersifat provan meskipun yang dihancurkan atau yang dibinasakan bukan benda. Dalam Kakawin Arjunawiwāha 4:1, disebutkan pada saat Arjuna menjalani brata atau bertapa, para bidadari diperintah oleh Dewa Indra untuk menghancurkan brata sang Arjuna (Wiryamartana,1990:125). "akweh tékapnya rumuwat brata pänquputra..." (banyak tingkah mereka untuk menghancurkan tapa Panduputra).

Pada masa Majapahit, kata ruwat banyak menghiasi karya sastra kakawin dan kidung. Dari segi fungsi sintatik, obyek kata ruwat mengalami pergeseran semantis yaitu dari materiil ke immateriil. Seperti dalam kakawin Kuñjarakarna 71:24, ditemukan kalimat: pamalaku rinuwat mala nyantěn i nghulun (mohon dihapuskan noda adik hamba). Atau dalam kidung Sudamala 1:14 yang menggunakan 
istilah lukat. " Lukat ni kapalang nikang sukrta marga nt kapalang ' denta dewati (pembebasan terhalang oleh perbuatan baik sebagai sebab bagimu terhalang dewati).

Menarik perhatian dalam kutipan di atas ditemukan pula kata sukrta, yang sampai sekarang kata itu masih digunakan dalam upacara tradisi ruwatan yang dikaitkan dengan bocah. Bocah sukerto hanya akan terbebas dari malapetaka jika dilakukan upacara ruwat Demikian pula kata sukrta ini muncul dalam kakawin Gatotkacâśraya 31:3. ...mawak sukrta duskrtanemahaken hala hayu sukha duhka ning dadi (...berpribadi baik atau jelek menyebabkan yang jahat ataupun yang baik suka dan duka bagi makhluk hidup).

Ruwat atau lukat terbukti banyak ditemukan dalam kitab Jawa kuno. Dalam kakawin Pārthayajka yang digubah sekitar abad XIV M ruwat dikaitkan dengan mala atau kotoran batiniah yang perlu dibersihkan. Salah satu bait penting dalam kakawin ini yang perlu dikutipkan secara lengkap untuk menjelaskan penyebab ruwatan, adalah sebagai berikut.

putu ńi ngulun lalu tekkapta dumaya dahat, katekan malånaputi manruwat sukha magon, wruh aku $n$ titah juga tinut nikan hala hayu, mapa pajarankva ri putunku mênaka réño. (PYn. 40:4)

Terjemahan:

cucuku, kelewattah olehmu sangat tidak bijaksana, kedatangan kotoran, menyelimuti, menghancurkan kebahagiaan yang agung.

mengertilah aku akan keadaan pasti, yang diikutt baik buruknya, perkenankanlah aku memberi pelajaran kepada cucuku, baik-baiklah mendengarkan(nya).

Dari kutipan bait di atas, tampak jelas ruwat dikaitkan dengan mala yang melekat dalam diri manusia dan dapat menghancurkan (manruwat) kebahagiaan abadi. Apakah penyebab dari kehancuran kebahagiaan abadi itu dan bagaimana manusia dapat melepaskan dari kehancuran sehingga dapat mencapai kebahagiaan kembali? Kakawin PărthayajKa bait $40: 4$ dalam adegan Bhagavan Dvaipåyana saat mengajarkan kepada Arjuna, dijelaskan.

mada raga moha ya musuhta nitya maparek.

ya ta lot mijil jagani rin sahisnu mudita. 
mabuk, nafsu, dan bingung adalah musuhmu yang selalu mendekat yang terus-menerus muncul, lindungilah dengan ketabahan dan kegembiraan.

Kutipan bait di atas, tampak jelas bahwa penyebab kehancuran manusia adalah mala yang terdiri atas mabuk, nafsu, dan bingung (mada, răga, moha). Sebaliknya mala dalam teks tersebut dapat dihancurkan dengan sarana sahisnu dan mudita yang menurut Manu Jayaatmaja (1996:7) diartikan sebagai bhakti. Sedangkan kata suhka magon atau kebahagian yang agung ini diartikan sebagai mokșha atau kelepasan abadi. Dengan demikian bhakti mampu menghancurkan mala yang berarti orang terhindar dari bhavacakra atau kelahiran kembali yang berarti pula manusia terhindar dari kekuasaan kala.

Dari kutipan teks-teks Jawa kuno di atas, secara semantis arti ruwat telah mengalami pergeseran dari arti provan ke arti sakral. Demikian pula tema kisah ruwat dalam naskah-naskah kuna di atas umumnya cenderung mengenai pembebasan mahluk sengsara yang semula dewa. Karena melakukan kesalahan dan menerima kutukan, maka dewa berubah menjadi binatang atau raksasa yang dapat berubah wujud sempurna kembali setelah diruwat oleh manusia. Jadi dalam konteks data tekstual tersebut, ruwat diperuntukkan kepada dewa sedangkan kedudukan manusia di sini justru sebagai pelaku penyelamat.

Ruwat, selain dibuktikan dalam data tekstual juga dibuktikan dalam seni pahat yang banyak ditemukan pada dinding candi masa Majapahit. Relief-releif pada Candi Surawana, Candi Tigawangi, dan Candi Sukuh, merupakan bukti paling klasik tentang cerita ruwat yang dicuplik dari Kidung Sudamala pada masa akhir Majapahit (abad XV M). Cerita ruwat ini mengisahkan usaha manusia (Sadewa) dalam membebaskan kesengsaraan Bathari Durga yang berwajah raksasi untuk berubah kembali sempurna menjadi Dewi Uma. Relief cerita ruwat pada candi-candi Majapahit dapat dilihat pada tabel di bawah ini: 


\begin{tabular}{|c|c|c|c|}
\hline Nama candi & Tahun & Nama Relief & $\begin{array}{l}\text { Lokasi } \\
\text { Pahatan }\end{array}$ \\
\hline Jago & $1343 M$ & $\begin{array}{l}\text { Kunjarakarna, } \\
\text { Parthayajna, } \\
\text { Ajunawiwaha }\end{array}$ & kaki, tubuh candi \\
\hline Tegawangi & $1370 \mathrm{M}$ & Sudamala & tubuh candi \\
\hline Kedaton & $1370 \mathrm{M}$ & $\begin{array}{l}\text { Ajunawiwaha } \\
\text { Garudeya }\end{array}$ & $\begin{array}{l}\text { tubuh candi } \\
\text { batur/teras candi }\end{array}$ \\
\hline Ngrimbi & $1384 M$ & Garudeya & kaki candi \\
\hline Surawana & $1440 M$ & Ajjunawiwaha & tubuh candi \\
\hline Penanggungan & \pm abad XV M & Nawaruci & panil, (hilang?) \\
\hline Sukuh & \pm abad XV M & $\begin{array}{l}\text { Sudamala } \\
\text { Garudeya }\end{array}$ & panil lepas \\
\hline
\end{tabular}

Tabel di atas memperlihatkan, cerita ruwat pada masa Majapahit banyak digemari masyarakat. Pemilihan cerita untuk dipahatkan pada relief candi jelas memiliki fungsi tertentu yang bukan hanya sekedar hiasan semata. Mengenai makna relief cerita ruwat dalam kaitannya dengan candi bukan pada tempatnya untuk dibahas di sini.

Pada awal abad XVII M, masa pemerintahan Seda Krapyak, diperoleh informasi, dalang Anjang Mas dari Mataram mengubah upacara ruwatan yang semula dilakukan dengan topeng atau wayang beber diubah dengan wayang kulit (Pigeaud,1963). Ruwat dengan permainan panggung wayang topeng ini pernah pula dimainkan di Gunung Kidul dengan lakon Jati Pitutur (Subali,1985:4). Dari informasi di atas dapat disimpulkan, ruwatan, pertama kali muncul hanya terbatas pada dewa, kemudian berkembang ke lingkungan istana. Semula upacara ruwatan menggunakan sarana wayang beber, kemudian dengan topeng, dan selanjutnya berkembang dengan menggunakan wayang kulit hingga sekarang.

Dari data tekstual di atas, dapat diduga upacara ruwatan yang terjadi sekarang merupakan kesinambungan dari tradisi yang sudah lama hidup dalam sistem kepercayaan masyarakat Jawa. Penelitian Manu (1996:18) terhadap kakawin Korawâsrama dan Mahäbãrata membuktikan hal itu. Menurutnya tradisi ritual ruwatan merupakan 
upacara diksa, yaitu penghancuran terhadap garbhe yang mengurung manusia. Dengan hancurnya garbha maka berarti manusia telah lahir dari kandungan dan hadir dalam bentuk kesejatiannya.

Secara filosofis upacara ruwatan berarti pembinasaan atau penghancuran kala atau dalam tradisi Bhagavadgita merupakan maya yaitu bayangan atau ilusi. Selama manusia masih terjerat oleh maya, mereka akan mengalami penderitaan terus-menerus. Oleh karena itu tidak mengherankan jika di Jawa, ruwatan dilaksanakan dengan wayang kulit bertokoh Kala yang dipentaskan dalam kelir, sehingga menimbulkan bayangan. Maya atau bayangan inilah yang dihancurkan oleh dalang, sehingga sukrta atau svikrta ini dapat terbebas dari lingkaran maya yang berarti terhindar dari samsara (lbid:20).

\section{Ruwatan Masa Kini}

Upacara ruwatan merupakan fakta kultural yang telah tumbuh dan berkembang sejak 11 abad silam dan mengalami proses perubahan sampai pada bentuknya yang sekarang ini. Pada awalnya ruwat memiliki arti provan kemudian mengalami pergeseran menuju ke hal-hal yang sakral. Demikian pula obyek ruwatan mengalami perubahan dari dewa ke manusia, selanjutnya diikuti adanya perubahan makna ruwat dari orientasi kesempurnaan surgawi ke orientasi duniawi. Obyek pelaku ruwat pun ikut berkembang tidak terbatas pada manusia sukerto atau manusia panas, melainkan segala sesuatu yang diangggap tidak berjalan normal, termasuk hubungan antar manusia dengan manusia dan manusia dengan alam.

Dari beberapa definisi kebudayaan ( \pm 150 definisi), penulis cenderung memilih definisi yang diajukan oleh Clifford Geert. Dia mengatakan: Kebudayaan adalah sebuah pola dari makna-makna yang tertuang dalam simbol-simbol yang diwariskan melalui sejarah. Kebudayaan adalah sebuah sistem dari konsep-konsep yang diwariskan dan diungkapkan dalam bentuk-bentuk simbolik dengan berkomunikasi, mengekalkan dan memperkembangkan pengetahuan tentang kehidupan ini dan bersikap terhadap kehidupan ini (Geertz, 1992).

Tidak mengherankan kalau Geertz juga mengingatkan bahwa hubungan antara manusia dengan kebudayaan seperti laba-laba yang terperangkap dalam jerat-jerat makna yang ditenunnya sendiri. Contoh dari dunia peruwatan berikut ini membantu menjelaskan bagaimana selama ini kebudayaan dengan simbol-simbolnya telah direkayasa oleh manusia dengan berbagai kemungkinan pemanfaatan. 
Realitas memperlihatkan upacara ruwatan yang merebak di Jawa umumnya tetap memiliki prosesual yang jauh berbeda dengan upacara-upacara selamatan biasa. Rangkaian upacara ruwatan memeriukan berbagai sarana prosesi yang lengkap, salah satunya adalah pagelaran wayang kulit berlakon khusus Wurwakala. Dengan demikian ruwatan memerlukan biaya yang tidak sedikit.

Pengertian ruwatan dan sukerto yang memiliki hubungan sebab akibat, menyebabkan beban dan dilema tersendiri bagi mereka yang percaya. Satu sisi penyelenggaraan upacara ruwat memerlukan biaya yang tidak sedikit, di sisi lain manusia sukerto menuntut pentingnya penyelenggaraan upacara ruwatan agar terhindar dari mara bahaya Untuk mengatasi hal ini, maka muncul pihak-pihak tertentu untuk menyelenggarakan upacara ruwatan secara masal. Guna menjaring para peserta ruwat, mereka mempublikasikan terlebih dahulu di berbagai media massa lengkap dengan persyaratan dan biaya yang diperlukan

Penyelenggaraan ruwatan masal memiliki fungsi positif ganda, di samping melestarikan warisan budaya leluhur, juga dapat membantu meringankan beban biaya bagi mereka yang lemah perekonomiannya. Lembaga Javanologi Panunggalan Yogyakarta sejak tahun 1990 setiap tahun menyelenggarakan upacara ruwatan masal dan berhasil menjaring antara 50-100 peserta setiap kali kegiatannya. Menarik perhatian, para peserta tidak hanya berasal dari Jawa tetapi juga dari luar Jawa (Soelist, 1993:181).

Sebagian masyarakat Jawa yang hingga saat ini masih mempercayai adanya ruwat, merasa gelisah hidupnya jika belum melaksanakan ruwatan terhadap anaknya yang sukerto (Subali,1985:3-5). Dalam kelompok masyarakat yang masih berpegang pada nilai-nilai budaya leluhur ini, tidak jarang setiap peristiwa kesusahan atau bencana rumah tangga yang beruntun menerpa seseorang, akan dikaitkan dengan kehadiran anak sukerto yang belum diruwat.

Kasus yang menimpa keluarga Bapak Slamet Riyadi dari Tegal Jawa Tengah, barangkali dapat dijadikan contoh tentang kegelisahan akibat keyakinan yang kuat terhadap makna ruwatan. Bapak ini memiliki dua anak laki-laki yang dalam pakem pangruwatan disebut ugeruger lawang, yaitu salah satu kriteria manusia panas atau sukerto yang harus diruwat. Menurutnya kedua anak itu sering bertengkar dan selalu membuat susah orang tua, sehingga keadaan keluarga tidak pernah tenteram. Pak Slamet menduga, penyebabnya adalah kedua anak itu belum diruwat. Akhirnya kegelisahan itu hilang setelah dia ikut meruwat anaknya pada upacara yang diselanggarakan Lembaga Javanologi Yogyakarta Juni 1993 lalu. Dia mengatakan, "Sebenarnya sudah sejak lama saya Ingin melakukan upacara ruwatan, tapi terben- 
tur soal biaya. Untunglah kami baca koran, di Yogyakarta ada ruwatan masal. Jika tidak, wah... kami pasti tidak akan mampu menyelenggarakannya sendiri. Lega hati saya dan beban saya seakan hilang. Semoga dengan ruwatan ini bencana yang selalu menimpa keluarga saya hilang. "(Ibid, 179).

Kasus Bapak Slamet di atas merupakan salah satu dari sekian banyak kasus serupa dalam kehidupan masyarakat Jawa. Mereka meyakini ruwatan merupakan upaya transendental yang sanggup menentramkan batin manusia yang gelisah karena konsep sukerto.

Kini, penyelenggara ruwatan tidak hanya terbatas pada lembagalembaga swasta yang bergerak dalam bidang kebudayaan, melainkan telah berkembang $k e$ individu-individu sebagai sponsor dan bahkan hotel-hotel berbintang atau perusahaan-perusahaan lainnya. Di sini tampak bahwa misi pelestarian warisan budaya telah tergeser oleh misi khusus yang beragam sifatnya, tergantung dari kepentingan pihak penyelenggara. Ini menunjukkan telah terjadi komoditisasi mitos ruwatan, sebab obyek pelaku tidak terbatas pada manusia sukerto saja, melainkan berbagai kondisi dan situasi yang dianggapnya tidak normal. Seperti upacara ruwatan yang dilakukan baru-baru ini terhadap kasus banyaknya seniman Yogyakarta yang kebetulan meninggal secara berturut- turut.

Satu contoh lain yang menarik adalah ruwatan yang dilakukan sehubungan dengan kekacauan penerbangan di bandara Adisucipta Yogyakarta. Akibat kekacauan yang disebabkan oleh kesalahan teknis, selama dua bulan (September - Oktober 1995) terjadi kecelakaan beruntun menimpa tiga buah pesawat terbang dari tiga perusahaan penerbangan besar. Dalam kecelakaan tersebut tidak ada korban, namun peristiwa ini dikaitkan dengan persoalan mistis yakni marahnya makhluk halus penunggu Bandara Adisucipto akibat terganggu oleh proyek pembangunan landasan pacu yang menelan biaya Rp. 4.1 milyar, maka perlu upacara ruwat (Gigin, 1993: 90).

Ruwatan masa kini nampaknya sudah menjadi semacam gaya hidup. Karena gaya hidup ini merupakan simbol prestise, maka bisa jadi aktivitas ini cenderung bersifat modis dan berunsur politis, sambil memanfaatkan slogan pelestarian kebudayaan tradisional. Konsep ruwatan semacam ini biasanya tidak akan bertahan lama dan hanya bersifat musiman. Namun demikian ada juga anggota masyarakat yang melakukan ruwatan karena memang masih berpegang pada nilai-nilai budaya leluhur. Atau paling tidak, upacara ruwatan merupakan sarana kepasrahan diri ketika rasio tidak bisa mengatasinya. Kelompok masyarakat yang demikian ini, melakukan upacara ruwatan 
bukan karena alasan gengsi atau prestise, melainkan percaya bahwa ruwatan adalah jawaban yang dianggap bisa menyelesaikan permasalahan. Seorang bapak dari Jakarta yang mengantarkan anaknya dalam upacara ruwatan yang diselenggarakan oleh lembaga Javanologi Yogyakarta pada Juni 1993 mengatakan:

"Ya, saya percaya pada ruwatan. Sudah lama saya diperintah oleh orang tua saya untuk meruwat anak saya, tetapi karena sibuk baru kali ini bisa kami lakukan." (Soelist, 1993)

- Dari Jakarta datang ke Yogyakarta hanya untuk mengantarkan upacara ruwatan anaknya merupakan fenomena yang menarik. Hal itu dilakukan karena bapak bernama Pujiarto itu memiliki masalah dengan anak perempuannya yang dalam pakem pangruwatan disebut sendang kaapit pancuran (tiga anak bersaudara, laki-laki - perempuan laki-laki). Masalah yang dihadapi mirip dengan masalah Pak Slamet dari Tegal tadi, yaitu anak perempuannya sering sakit-sakitan dan ada saja peristiwa yang mengganggu ketenangan keluarga akibat ulah anak perempuannya tersebut. Pak Pujiarto menambahkan keterangannya: "Saya puas dan lega bisa memenuhi amanat orang tua saya untuk meruwat anak saya, sekaligus ingin membuktikan adanya perubahan suasana dalam keluarga dengan selesainya ruwatan itu nanti."

Harapan adanya perubahan di atas, menurut Karkono Kamajaya tidak dapat menjamin sepenuhnya bahwa setelah anak diruwat akan benar-benar menghapus segala mara bahaya dalam dirinya maupun lingkungan keluarganya. Di dalam upacara ruwatan yang terpenting adalah pemahaman makna simbolis yang terungkap dalam upacara maupun pagelaran wayang. Di sini anak mendapat pembekalan berbagai ajaran etik dan moral, bahwa dalam kehidupan manusia berlaku hukum adikodrati : siapa yang patuh akan selamat, sebaliknya yang melanggar akan mengalami kesengsaraan (Karkono, 1992).

\section{Transformasí Makna}

Masih banyak orang membayangkan, kebudayaan sebagai sesuatu yang berhenti pada suatu puncak pencapaian prestasi dan kemudian berakar dengan kukuhnya seakan tidak beranjak lagi. Dalam konteks yang demikian ini tradisi ruwat sebagai bagian kecil dari budaya manusia, dibayangkan sebagai penjaga kelestarian budaya yang membelenggu dan mengikat masyarakat. Kesalahan semacam itu, bersumber pada pemahaman budaya sebagai sesuatu yang tidak 
mungkin berubah dan berkembang menjadi sesuatu yang berbeda sosoknya. Dengan demikian kebudayaan dibayangkan sebagai suatu kemutlakan, suatu ciri yang akan terus melekat pada tubuh masyarakat untuk selamanya.

Mengacu pada pandangan Geertz (1978:89) bahwa kebudayaan bersifat dinamis, maka upacara ruwatan sebagai tradisi dengan sendirinya akan mengalami perkembangan sesuai dengan dinamika dari sistem nilai dalam masyarakat. Dialog dialektis antara masyarakat dengan sistem nilai itulah yang menurut Umar Khayam, antara lain membuat kebudayaan menjadi suatu sistem yang dinamis dan tidak tegar (Khayam,1987.312). Perubahan makna ruwatan selain pada sifat, obyek, dan lingkungan (lihat bab 3 ) juga dari segi ritus upacara. Ritus upacara ruwatan, kini dapat dilakukan di mana saja termasuk di hotel-hotel berbintang dengan dilatari tujuan politis, yaitu untuk kepentingan pariwisata.

Mengamati pergeseran makna ruwatan dewasa ini, tampak jelas bahwa kekuatan kebudayaan sebagai sistem kognitif dan sistem normatif telah menipis. Peranannya kini hanya sebagai "penyerta" yang berfungsi sebagai hiasan lahiriah, tidak fungsional terhadap cara pikir dan cara tingkah laku. Namun demikian ruwatan masih menentukan bagaimana seseorang atau sekelompok orang memperlihatkan diri. Ibarat drama, ruwatan sebagai bagian kecil dari budaya, tidak lagi berfungsi sebagai skenario, tetapi sebagai decor theatral, atau setting yang diperlukan hanya untuk menciptakan suasana. Pada titik ini budaya ruwatan berhenti sebagai pandangan hidup dan hanya berperanan sebagai gaya hidup.

Fenomena gaya hidup yang penyebarannya melalui media massa, diprediksikan sebagai "kebudayaan massa". Suatu gaya hidup yang meluas lewat media massa ini dapat saja melahirkan pola kehidupan yang demokratis. Dengan kata lain suatu gaya hidup tidak lagi menjadi previlese suatu kelompok etnis atau dalam stratifikasi sosial tertentu. Dalam konteks kebudayaan massa, masyarakat dapat menjadi homogen. Siapa saja dapat mengikutinya, tak terbatas dari kelompok etnis tertentu. Mereka dapat memenuhi keinginannya untuk mengidentifikasikan dirinya ke dalam suatu kelompok sosial yang dicitrakan oleh budaya ruwatan tersebut. Gejala semacam itu kini sudah tampak, terbukti dalam beberapa upacara ruwatan masal di Jawa Tengah, pesertanya berasal dari berbagai daerah di luar Jawa, bahkan Cina dan orang asing lainnya.

Terlepas dari misi penyelenggaraan ruwatan masal sebagaimana diuraikan di atas, banyaknya orang Jawa yang melakukan ruwatan didasari pada kepercayaan mereka yang masih mempercayainya. 
Kasus Pak Pujiarto dari Jakarta atau Pak Slamet Riyadi pedagang dari Tegal di atas, adalah contoh kuatnya konsep ruwatan sebagai pemecahan masalah akibat gangguan dari manusia sukerto. Atau paling tidak ruwatan sebagai simbol penghargaan terhadap suatu gejala perubahan yang tidak terduga. Ketika rasio sudah tidak sanggup memecahkan, maka ruwatan merupakan cara terbaik untuk memasrahkan diri dengan harapan segalanya pulih kembali. Bagaimanapun aktivitas ceremonial ini akan mampu memberikan dampak psikologis bagi yang percaya dan melaksanakannya 
Gigin, 1995. Bila Bandara Adi Sucipto Diruwat. Liberty No. 1865, 20 Februari 1995. Hal. 90 - 91.

Geertz,Clifford.,1978 The Interpretation of Cultures. New York, Basic Books Inc.

Kamajaya, Karkono., 1992. Ruwatan Murwakala Suatu Pedoman, Yogyakarta, Duta Wacana University Press.

Kayam,Umar. 1978. Kebudayaan dan Pembangunan dalam Kebudayaan dan Pembangunan Sebuah Pendekatan Terhadap Antropologi Terapan di Indonesia. Jakarta, Yayasan Obor Indonesia.

Kompas, 25 Mei 1996, Ruwatan Merebak di Jawa Tengah/DIY.

Pigeaud, Th. G. Th.1962. Java in the 14 Century. A study in Cultural History Vol III. Translation The Hague: Martinus Nijhoff.

Soepadjar,Damardjati.1992. Nilai kefilsafatan Upacara Ruwatan Dalam Karkono Kamajaya (dkk) Ruwatan Murwakala: Suatu Pedoman. Yogyakarta: Duta Wacana University Press.

Subalidinata,dkk.1985. Sejarah dan Perkembangan Cerita Murwakala dari Sumber-Sumber Sastra Jawa. Yogyakarta, Departemen Pendidikan dan Kebudayaan Proyek Penelitian dan Pengkajian Kebududayaan Nusantara

Soelist, B. 1993. Ruwat Sebuah Ungkapan Kepasrahan. Intisari, September, hal. 176- 190.

Zoetmulder,PJ.1982. Old Javanese-English Dictionary Leiden:Koninklijk Instituut Voor Tall, Land en Volkenkunde, 's-GravenhageMartinus Nijhoff.

1983. Kalangwan Sastra Jawa Kuno Selayang Pandang,

Terjemahan Dick Hartoko SJ. jakarta: Jembatan. 